\title{
Upaya Edukasi Kesehatan Reproduksi Kepada Anak Usia Remaja Di Sekolah Menengah Atas Swasta Army Putra Makassar
}

\author{
Ani ${ }^{1 *}$, Sudirman ${ }^{2}$ \\ $1^{*}$ Program Studi D-IV Kebidanan, Sekolah Tinggi Ilmu Kesehatan Graha Edukasi Makassar, Jalan \\ Perintis Kemerdekaan, Kota Makassar, Provinsi Sulawesi Selatan, Indonesia. \\ 2 Program Studi Kesehatan Masyarakat, Sekolah Tinggi Ilmu Kesehatan Indonesia Jaya, Jalan \\ Towua No.114, Birobuli Sel, Kota Palu, Provinsi Sulawesi Tengah, Indonesia. \\ Corresponding Email: safaniani@gmail.com 1*.
}

\author{
Article History: \\ Received: Dec 07th 2021 \\ Revised: Dec 14th 2021 \\ Accepted: Dec 18th 2021 \\ Published: Jan 1th 2022 \\ Keywords: Education; \\ Youth Students; \\ Reproductive Health.
}

\begin{abstract}
Reproductive health is a condition in which a person is physically and mentally and socially healthy which is directly related to the reproductive process in adolescent girls or boys. Knowledge related to reproductive health in adolescents at an early age is very useful to prevent free sex behavior. This service activity has been carried out for 2 days from 18 to 19 October 2021 for 89 participants. a total duration of 8 hours, held at SMAS Army Putra Makassar. Teenagers have a very high curiosity about their reproductive health and teenage students are enthusiastic about receiving reproductive health materials, the topics most teenagers want to know are related; various diseases that can attack the reproductive organs, how to take care of the cleanliness of intimate organs, sexual problems and how to prevent free sex behavior. Most of the teenage students of SMAS Army Putra Makassar have received educational materials related to reproductive health but still need assistance regarding reproductive health.
\end{abstract}




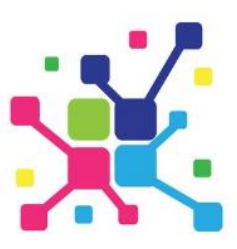

\section{Pendahuluan}

Anak yang memasuki usia remaja akan mengalami perubahan dan peralihan secara biologis dan psikologis dari fase usia anak-anak menuju fase usia dewasa. Fase remaja umumnya pada usia 10 sampai dengan 22 tahun, fase remaja merupakan masa seorang anak memiliki keinginan yang tinggi untuk mengetahui hal-hal baru secara biologis dan psikologis. Keingintahuan remaja yang tinggi akan berisiko jika tidak terkontrol atau tanpa bekal pemahaman kesehatan reproduksi sebelumnya, hal tersebut dapat terjadi karena emosi remaja yang masih sangat labil sehingga dapat menjerumuskan pada pergaulan yang negatif. Secara biologis dan psikologis pergaulan yang negatif dapat memicu perilaku seks bebas pada anak remaja yang dapat mengakibatkan penularan penyakit seksual [1].

Kesehatan reproduksi merupakan suatu keadaan di mana seseorang yang memiliki keadaan yang sehat secara fisik dan mental serta sosial yang secara langsung berkaitan dengan proses reproduksi pada remaja perempuan atau laki-laki [2]. Pengetahuan terkait kesehatan reproduksi pada anak usia remaja secara dini sangat bermanfaat untuk mencegah perilaku seks bebas. Kesehatan reproduksi pada kalangan anak remaja saat ini belum mendapatkan perhatian yang cukup, sehingga anak pada fase usia remaja menganggap pengetahuan terkait kesehatan reproduksi masih sangat tabu atau rahasia [3].

Peran serta dan perhatian setiap pihak untuk memberikan pengetahuan tentang kesehatan reproduksi secara dini pada anak remaja merupakan poin yang sangat penting. Anak pada fase remaja, umumnya belum dapat mempertanggungjawabkan dampak dari perilaku yang dilakukan, khususnya yang berkaitan dengan kesehatan reproduksi yang dapat terjadi kapan saja pada anak usia remaja, risiko perilaku seks bebas seperti; penularan penyakit seksual, pelecehan seksual, dan aborsi [4].

Seorang anak yang memasuki fase usia remaja akan menghadapi periode pubertas sehingga perilaku seksual yang di perlihatkan akan mengalami perubahan di mana anak remaja mulai menunjukkan tindakan yang menarik perhatian lawan jenisnya dengan tujuan untuk mengeksplorasi serta mencari atau menambah pengetahuannya terkait seks dalam pergaulannya [4].

Pubertas anak remaja akan berdampak pada tingginya kejadian perilaku seks bebas apabila tidak mendapatkan perhatian serius dari berbagai pihak, hal tersebut akan berdampak pada rusaknya norma dan budaya sosial ditengah masyarakat, pendidikan kesehatan reproduksi untuk menambah pengetahuan harus di berikan secara dini kepada setiap anak yang telah memasuki fase usia remaja, terutama di lingkungan keluarga dan sekolah, agar dapat menjadi pertimbangan dalam bergaul sehingga terhindar dari perilaku seks bebas.

Berdasarkan pada kajian informasi yang telah dilakukan oleh tim pengabdi, sehingga kegiatan pengabdian masyarakat "Upaya Edukasi Kesehatan Reproduksi Kepada Anak Usia Remaja Di Sekolah Menengah Atas Swasta Army Putra Makassar" telah 


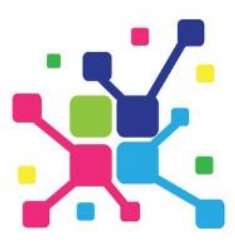

A J A D

Jurnal Pengabdian kepada Masyarakat

Vol. 2, No. 1, May, 2022, pp. 40-47

DOI : https://doi.org/10.35870/ajad.v2i1.29

dilakukan dengan pertimbangan bahwa anak pada jenjang Sekolah Menengah Atas merupakan fase usia pubertas karena telah memasuki usia remaja dan berisiko tinggi berperilaku seks bebas. Kegiatan pengabdian ini bertujuan agar memberikan bekal pemahaman secara dini pada anak usia remaja dan dapat bermanfaat sebagai pemberi contoh terhadap teman sejawatnya dalam bergaul.

\section{Metode}

a. Metode Pelaksanaan Kegiatan

Kegiatan di lakukan dengan model ceramah dan diskusi secara bersesi kepada 89 orang siswa dan siswi, sesi pertama sebanyak 44 orang dan sesi kedua sebanyak 45 orang. Proses kegiatan pengabdian ini dapat di lihat pad Gambar 1 berikut.

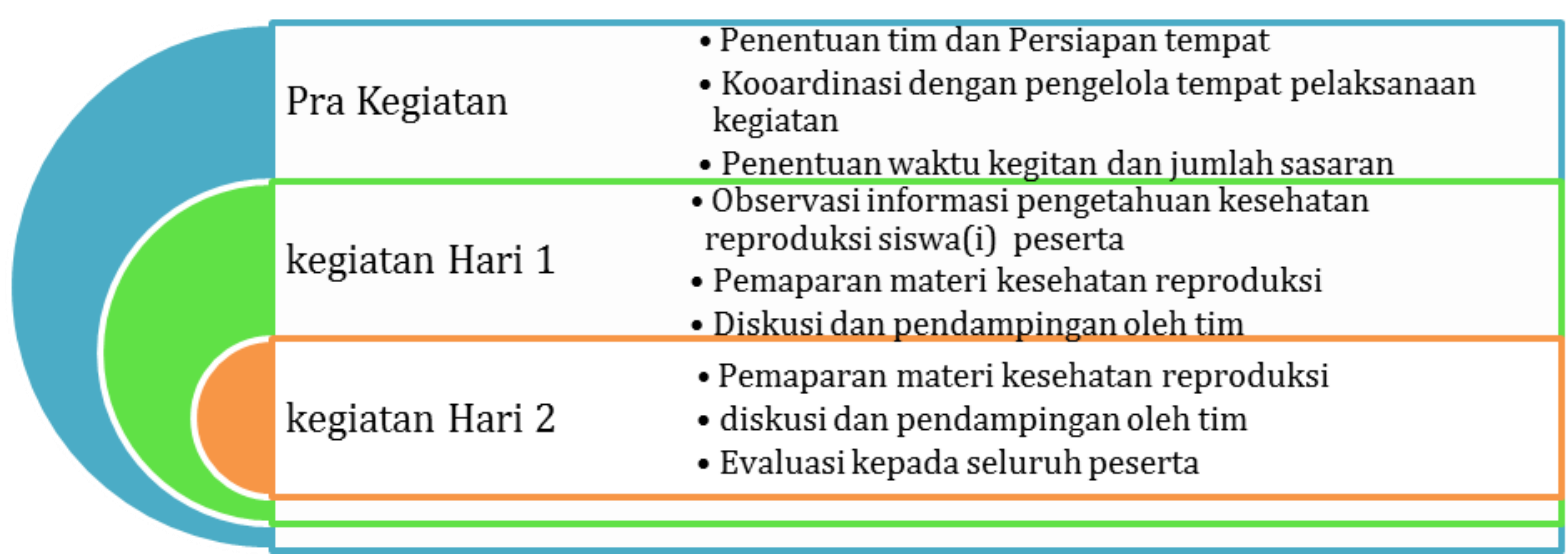

Gambar 1. Proses kegiatan pengabdian

b. Waktu Efektif Pelaksanaan Kegiatan

Kegiatan pengabdian ini telah dilaksanakan selama 2 (dua) hari sejak tanggal 18 hingga 19 Oktober Tahun 2021 dengan total durasi waktu selama 8 jam.

c. Tempat Kegiatan

Pelaksanaan Kegiatan di Sekolah Menengah Atas Swasta (SMAS) Army Putra Makassar. 


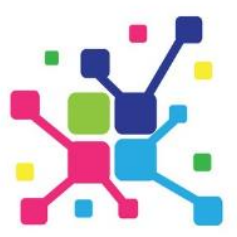

\section{Hasil}

Kegiatan ini telah dilaksanakan selama 2 hari, Pelaksanaan pemberian informasi atau materi terkait kesehatan reproduksi kepada siswa-siswi SMAS Army Putra Makassar berjalan sesuai harapan, seluruh siswa siswi remaja yang hadir, berperan aktif dalam pelaksanaan kegiatan. Proses kegiatan dapat di lihat pada gambar-gambar berikut;
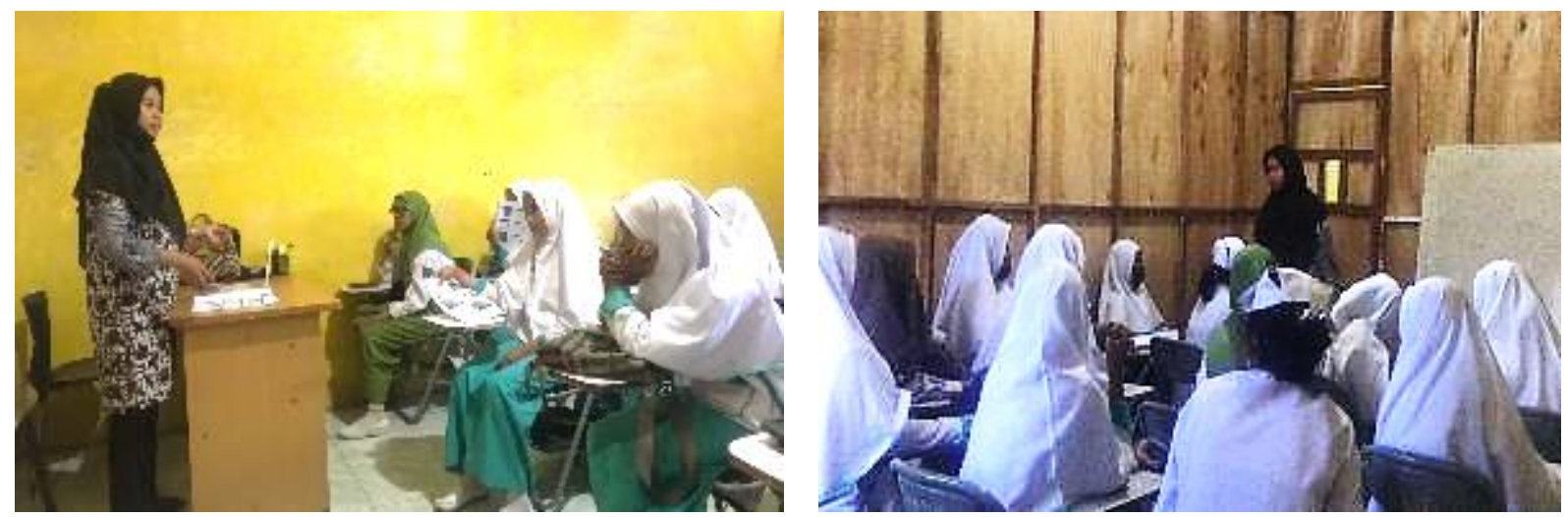

Gambar 2. Pemberian materi kesehatan reproduksi kepada siswa-siswi remaja SMAS

\section{Army Putra Makassar}

Proses penyampaian materi kesehatan reproduksi para siswa-siswi remaja SMAS Army Putra Makassar terlihat sangat antusias dan fokus dalam menerima materi. Materi kesehatan reproduksi yang di berikan kepada audiens memuat komponen terkait;
a. Pengertian Remaja
b. Pengertian Kesehatan Reproduksi
c. Faktor-faktor yang mempengaruhi kesehatan reproduksi
d. Konseling, informasi dan edukasi (KIE) kesehatan reproduksi
e. Perubahan Fisik, Biologis, Psikososial pada usia remaja
f. Risiko perilaku seksual
g. Psikologi remaja
h. Strategi Meningkatkan dan menjaga kesehatan reproduksi

Setelah proses pemberian materi diharapkan bagi seluruh siswa-siswi remaja di SMAS Army Putra Makassar dapat memiliki pengetahuan terkait kesehatan reproduksi dan terhindar dari perilaku seksual berisiko. Menurut beberapa hasil penelitian terkait bahwa kelompok usia remaja merupakan salah satu bagian masyarakat dengan keinginan untuk tahu terhadap sesuatu hal sangat tinggi, sehingga sangat penting untuk dibekali informasi terkait kesehatan khususnya kesehatan reproduksi dan risiko seksualitas yang di timbulkan [5]. Umumnya remaja siswa-siswi masih sangat minim pengetahuan dan pengalaman terkait kesehatan reproduksi, adapun siswa-siswi yang telah mengetahui atau telah mendapatkan informasi dari berbagai sumber namun masih belum memiliki kesadaran untuk melakukan atau menerapkannya [6].

Pendidikan yang diberikan kepada peserta siswa-siswi akan mengalami penyerapan yang berbeda-beda antara setiap peserta yang lain karena disebabkan oleh 


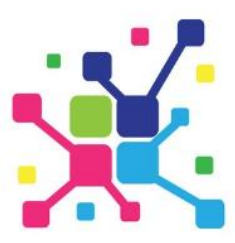

berbagai faktor, seperti tingkat pemahaman, metode yang di gunakan, dan cara implementasi ceramah yang satu arah atau tanpa ada feedback diskusi dari siswa-siswi [7].

Setelah pemberian materi kepada para audiens siswa-siswi remaja SMAS Army Putra Makassar di lanjutkan dengan sesi diskusi atau tanya jawab seputar materi kesehatan reproduksi bagi anak remaja, proses diskusi dapat di lihat pada gambar 3.
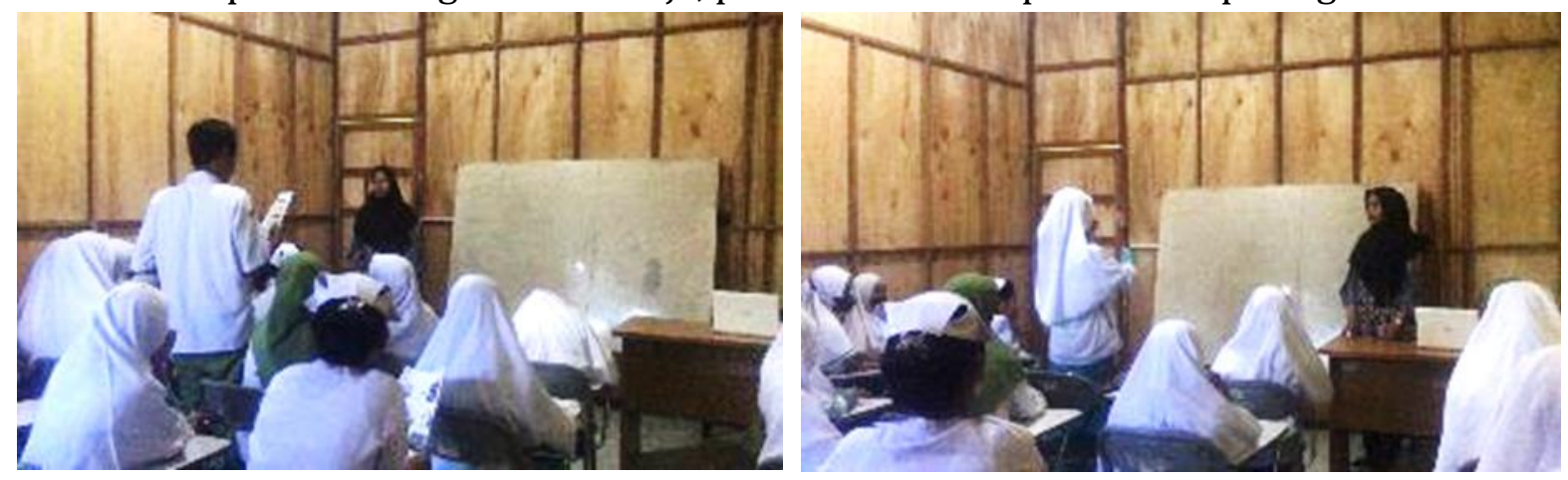

Gambar 3. Proses diskusi dan tanya jawab

Dalam proses diskusi dapat terlihat bahwa anak usia remaja memiliki rasa ingin tahu yang sangat tinggi mengenai kesehatan reproduksinya dan hampir seluruh siswasiswi remaja sangat antusias bertanya. Hal-hal yang menjadi topik yang paling banyak di tanyakan atau di ulas yaitu terkait; macam-macam penyakit yang dapat menyerang alat reproduksi, cara merawat kebersihan organ intim, masalah seksual serta cara mencegah perilaku seks bebas.

Antusiasme peserta didik menjadi indikasi bahwa anak yang telah berusia remaja sangat memerlukan edukasi terkait kesehatan reproduksi yang benar serta membutuhkan sarana untuk melakukan konseling secara nyaman terkait perubahanperubahan yang di alami secara fisik dan psikologis [8]. Secara umum kebudayaan yang berkembang di Indonesia menunjukkan bahwa sikap atau perilaku seksual bebas adalah hal yang terlarang dan tidak terpuji, sehingga untuk membangun pengetahuan yang positif kepada remaja terkait seks bebas menjadi terbantu serta dukungan religius di lingkungan keluarga yang mengharamkan perilaku seksual bebas juga sangat membantu untuk membangun sikap positif pada remaja terhadap perilaku seksual pra nikah [9].

Setelah proses penyajian materi dan diskusi terkait materi kesehatan reproduksi selanjutnya dilakukan evaluasi untuk mengetahui seberapa luas pengetahuan yang di miliki oleh siswa-siswi remaja SMAS Army Putra Makassar, proses evaluasi dapa di lihat pada gambar 4. Berikut; 


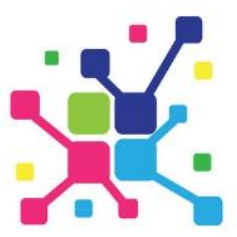

A J A D

Jurnal Pengabdian kepada Masyarakat

Vol. 2, No. 1, May, 2022, pp. 40-47 DOI : https://doi.org/10.35870/ajad.v2i1.29

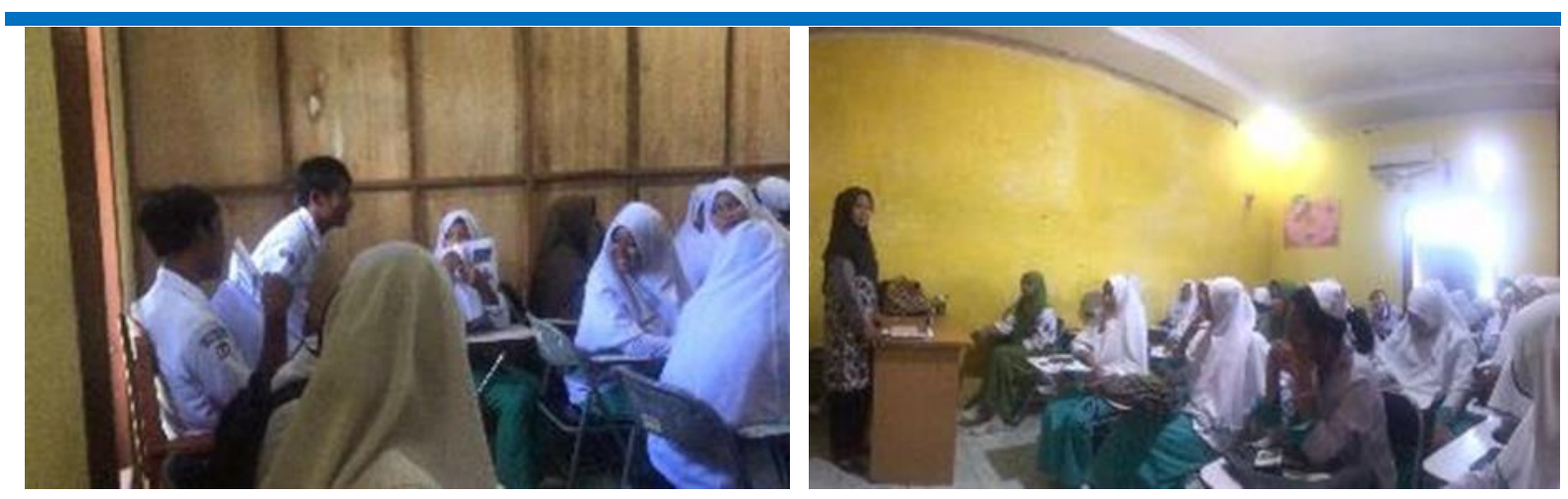

Gambar 4. Proses evaluasi materi

Dalam proses evaluasi terlihat bahwa sebagian besar siswa-siswi remaja SMAS Army Putra Makassar telah memiliki pemahaman yang baik dan positif terkait kesehatan reproduksi. Diharapkan selanjutnya siswa-siswi yang telah memahami seputar informasi tentang kesehatan reproduksi agar ke depannya dapat menjadi kader pendidik sebaya bagi siswa-siswi yang lainnya yang belum memiliki pemahaman serta siswa-siswi yang belum mengetahui sepenuhnya tentang kesehatan reproduksi, sehingga potensi perilaku seksual yang negatif dapat di cegah.

Fase usia remaja merupakan masa-masa yang sangat berarti dan berharga sehingga anak remaja harus terus di dampingi agar selalu mendapatkan kesehatan baik fisik maupun psikis dan akses pendidikan yang berkualitas karena di masa ini anak remaja mengalami growth spurt serta pubertas sehingga perlu di beri perhatian lebih dari segala aspek [10]. Hasil penelitian searah menunjukkan hasil bahwa pengetahuan kesehatan reproduksi dan seksual pada remaja sangat berpengaruh dan berisiko berperilaku seks pra-nikah yang negatif, anak remaja sangat penting di beri pengetahuan kesehatan reproduksi agar memahami secara benar proses reproduksi dan faktor-faktor yang berisiko negatif di sekitarnya, agar remaja memiliki perilaku yang dapat di pertanggung jawabkan [11].

Edukasi oleh teman sebaya menjadi strategi yang cukup efektif untuk memotivasi para remaja agar memiliki kesadaran mengenai kesehatan reproduksi dan pemahaman yang cukup agar anak usia remaja terhindar dari ketabuan menghadapi permasalahan kesehatan reproduksi setelah beranjak remaja [8].

\section{Kesimpulan}

Siswa-siswi remaja SMAS Army Putra Makassar sebagian besar telah mendapatkan edukasi terkait kesehatan reproduksi namun masih sangat memerlukan edukasi dan pendampingan terkait kesehatan reproduksi. Diharapkan bagi pihak sekolah menengah atas (SMA) secara umum agar membentuk pos kesehatan remaja dan sebagai wadah untuk mengedukasi dan mengontrol perilaku seksual remaja yang menyimpang. 


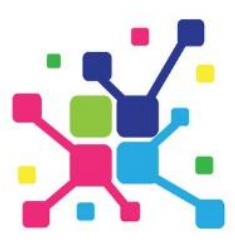

\section{Ucapan Terima Kasih}

Kami mengucapkan banyak terimakasih kepada pihak sekolah SMAS Army Putra Makassar atas kerja samanya sehingga kegiatan ini dapat terlaksana dengan lancar. Selanjutnya ucapan terimakasih kami ucapkan kepada pihak institusi STIKES Graha Edukasi Makassar yang telah memberikan dukungan moril dan moral demi kelancaran proses kegiatan ini, serta teman-teman pendidik yang telah berpartisipasi meluangkan waktu untuk membantu perencanaan dan proses kegiatan ini.

\section{Daftar Referensi}

[1] Yuliana, M. et al., 2020. Pemberdayaan Remaja Dalam Optimalisasi Peningkatan Pengetahuan Tentang Kesehatan Reproduksi Remaja Melalui Program Pojok Remaja Di SMAN 1 Cileunyi. Jurnal Pengabdian Masyarakat Kebidanan, 2(2), p. 31.

[2] KEMKES RI, 2014. Kesehatan Remaja. [Online] Available at: https://promkes.kemkes.go.id/content/?p=1510

[Diakses 14 November 2021].

[3] Jannah, M., 2018. Penyuluhan Kesehatan Reproduksi Remaja Di SMA SANTIKA Cipayung Jakarta Timur. Jurnal Pelayanan dan Pengabdian Masyarakat, 2(2), pp. 17.

[4] Sari, C. K. \& Dahlia, I., 2021. Pendidikan Kesehatan Reproduksi Terhadap Pengetahuan Seks Bebas Remaja. Jurnal Delima Hharapan, 8(1), pp. 27-32

[5] Matahari, R., Isni, K. \& Utami, F. P., 2021. Pemberdayaan Kesehatan Reproduksi Remaja Anggota Bina Keluarga Remaja (BKR) melalui Participatory Rural Appraisal (PRA) di Desa Potorono, Kabupaten Bantul, Daerah Istimewa Yogyakarta. Engagement, 5(1), pp. 196-206.

[6] Rohmah, E. \& Jannah, F. N., 2018. Relationship Of Knowledge About Adolescent Reproductive Health (ARH) With The Maintenance Of The Reproductive Organs Of The Female Students In Class XI SMA N 1 Badegan Ponorogo. Jurnal Delima Harapan, 3(1), pp. 18-27.

[7] Wicaksana, E. J., Atmadja, P. \& Asmira, Y., 2020. Pengembangan Poster Kesehatan Reproduksi Berbasis Pendidikan Karakter Menggunakan Canva pada Usia Remaja Sekolah di SMA. e-Saintika, 4(2), pp. 160-172.

[8] Sukaesih, N. S., Pramajati, H., Sopiah, P. \& Lindayani, E., 2020. Peningkatan Pengetahuan dan Kesadaran tentang Kesehatan Reproduksi Remaja Perempuan Melalui Program Pendampingan Teman Sebaya di Wilayah Kerja Puskesmas Cimalaka. E-DIMAS: Jurnal Pengabdian kepada Masyarakat, 11(4), pp. 405-413. 
[9] Oktiva, Y. D. \& Muhlisin, A., 2017. Hubungan Antara Tingkat Pengetahuan Tentang Kesehatan Reproduksi Remaja Dan Pola Asuh Orang Tua Dengan Sikap Remaja Tentang Seks Bebas Di SMA N 1 Tawangsari Sukoharjo. [Online] Available at: https://journals.ums.ac.id/index.php/BIK/article/view/3769 [Diakses 12 November 2021].

[10] Pratiwi, W. R., Hamdiyah \& Asnuddin, 2020. Deteksi Dini Masalah Kesehatan Reproduksi Melalui Pos Kesehatan Remaja. Jurnal Inovasi Hasil Pengabdian Masyarakat (JIPEMAS), 3(7), pp. 87-94.

[11] Yusti, E., Wijanarka, A. \& Ashari, A., 2020. Effectivness Of Android Applications Of Adolescent Reproduktive Health Against Improvement Of Premartial Sexual Behavior In Smk X Yogyakarta. Journal Health of Studies, 4(1), pp. 96-103. 